\title{
Silicate:nitrate ratios of upwelled waters control the phytoplankton community sustained by mesoscale eddies in sub-tropical North Atlantic and Pacific
}

\author{
T. S. Bibby and C. M. Moore
}

School of Ocean and Earth Sciences, National Oceanography Centre, Southampton, University of Southampton, European Way, Southampton, SO14 3ZH, UK

Received: 27 September 2010 - Published in Biogeosciences Discuss.: 14 October 2010

Revised: 11 February 2011 - Accepted: 2 March 2011 - Published: 14 March 2011

\begin{abstract}
Mesoscale eddies in sub-tropical gyres physically perturb the water column and can introduce macronutrients to the euphotic zone, stimulating a biological response in which phytoplankton communities can become dominated by large phytoplankton. Mesoscale eddies may therefore be important in driving export in oligotrophic regions of the modern ocean. However, the character and magnitude of the biological response sustained by eddies is variable. Here we present data from mesoscale eddies in the Sargasso Sea (Atlantic) and the waters off Hawai'i (Pacific), alongside mesoscale events that affected the Bermuda Atlantic TimeSeries Study (BATS) over the past decade. From this analysis, we suggest that the phytoplankton community structure sustained by mesoscale eddies is predetermined by the relative abundance of silicate over nitrate $\left(\mathrm{Si}^{*}\right)$ in the upwelled waters. We present data that demonstrate that mode-water eddies (MWE) in the Sargasso Sea upwell locally formed waters with relatively high $\mathrm{Si}^{*}$ to the euphotic zone, and that cyclonic eddies in the Sargasso Sea introduce waters with relatively low $\mathrm{Si}^{*}$, a signature that originated in the iron-limited Southern Ocean. We propose that this phenomenon can explain the observed dominance of the phytoplankton community by large-diatom species in MWE and by small prokaryotic phytoplankton in cyclonic features. In contrast to the Atlantic, North Pacific Intermediate Water (NPIW) with high $\mathrm{Si}^{*}$ may influence the cyclonic eddies in waters off Hawai' $\mathrm{i}$, which also appear capable of sustaining diatom populations. These observations suggest that the structure of phytoplankton communities sustained by eddies may be related to the
\end{abstract}

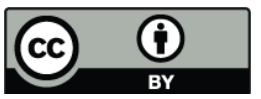

Correspondence to: T. S. Bibby

(tsb@noc.soton.ac.uk) chemical composition of the upwelled waters in addition to the physical nature of the eddy.

\section{Introduction}

Coupling between physical and biological processes in oceanic systems sets constraints on primary production in the upper ocean that control both the energy entering the ecosystem and the potential amount of carbon exported from the upper ocean via the biological carbon pump (Ducklow, 2001; Volk and Hoffert, 1985). Mesoscale eddies provide a mechanism of physical-biological coupling (McGillicuddy et al., 1999; Oschlies, 2002; Oschlies and Garcon, 1998) that may be particularly significant in the large oligotrophic gyres such as the North Atlantic Sub-Tropical Gyre (NASG), where estimates of export flux made locally are lower than geochemical estimates (Jenkins et al., 1988). Three main types of mesoscale eddy have been studied in the Sargasso Sea: mode-water eddies (MWE) and cyclonic eddies that cause an upward displacement of the seasonal-thermocline, and anticyclonic eddies that cause a downward displacement of the seasonal-thermocline. MWE and cyclonic mesoscale eddies can lift macronutrients into the euphotic zone and stimulate a biological response in the phytoplankton community, leading to enhanced export (McGillicuddy et al., 2007).

The episodic introduction of macronutrients from mesoscale eddies is thought to both stimulate phytoplankton growth and induce a shift from smaller to larger phytoplankton, which may subsequently export carbon from the euphotic zone more efficiently (Bibby et al., 2008; Brown et al., 2008; Mouriño-Carballido, 2009; Vaillancourt et al.,

Published by Copernicus Publications on behalf of the European Geosciences Union. 
2003). Such changes in community composition, enhanced production and export have been reported from a wide variety of mesoscale eddies. However, the character and magnitude of biological responses are variable, probably owing to the transient nature of eddies (Benitez-Nelson et al., 2007; Falkowski et al., 1991; Martin and Pondaven, 2003; McGillicuddy et al., 2007; Oschlies, 2002; Oschlies and Garcon, 1998). An interesting observation from recent studies is the difference in phytoplankton community composition that is maintained in both MWE and cyclonic eddies in the Sargasso Sea region of the NASG. MWE can sustain large-diatom communities dominated by species such as Chaetoceros spp., which are rare for the region, while cyclonic eddies are dominated by small prokaryotic phytoplankton that are more typical of the region (Bibby et al., 2008, 2009; Mouriño-Carballido, 2009; Ewart et al., 2008). In addition, measures of biogenic silicate production (0.9-1.1 $\left.\mathrm{mmol} \mathrm{Si} \mathrm{m}^{-2} \mathrm{~d}^{-1}\right)$ and accumulation (15-20 $\mathrm{mmol} \mathrm{Si} \mathrm{m}^{-2}$ ) in a MWE in the Sargasso Sea have been reported that are six times greater than those recorded for the nearby Bermuda Atlantic Time-Series Study (BATS) site (Krause et al., 2010). Correspondingly, the estimated biogeogenic $\mathrm{SiO}_{2}$ export rate of $1.27 \mathrm{mmol} \mathrm{Si} \mathrm{m}^{-2} \mathrm{~d}^{-1}$ in this MWE was 20 times higher than the BATS average, suggesting that MWE can maintain substantial diatom growth and export (Krause et al., 2010). Two studies over 3-yr (Sweeney et al., 2003) and 9-yr (Mouriño-Carballido, 2009) periods observed a total of 8 MWE, 13 cyclonic eddies and 6 anti-cyclonic eddies that affected the BATS station. In these studies, only MWE features were shown to sustain significant diatom communities; for example, Mouriño-Carballido reported a statistically significant difference in the contribution of diatom pigments to the total chlorophyll- $a$ concentration integrated over the top $160 \mathrm{~m}$ of the water column in MWE compared with cyclonic eddies that had affected the BATS site between 1993 and 2002 (Mouriño-Carballido, 2009). While the age of eddy features may have an important role in determining the phytoplankton community composition (Rii et al., 2008; Sweeney et al., 2003), the species differences between MWE and cyclonic eddies in the Sargasso Sea appear to be robust. A potential mechanism that has been proposed to account for the difference in overall magnitude of biological response between MWE and cyclonic eddy communities in the Sargasso Sea involves the effects of wind stress. Wind stress causes enhanced upwelling at the centre of MWE and downwelling in cyclonic eddies. This can persist throughout the lifetime of the eddy and thus sustain larger biological signals in MWE than cyclonic eddies (McGillicuddy et al., 2007; Martin and Pondaven, 2003). However, in contrast to the situation in the Atlantic, cyclonic eddies studied in the North Pacific Sub-Tropical Gyre (NPSG) have been shown to sustain high numbers of large diatoms for long periods and may even be active mechanisms of silica export in this region (Benitez-Nelson et al., 2007).
Recently, $\mathrm{Si}^{*}$, the difference between available silicate $\left[\mathrm{Si}(\mathrm{OH})_{4}\right]$ and nitrate $\left[\mathrm{NO}_{3}^{-}\right]$, has been used as a tracer of the return path of deep waters upwelled in the Southern Ocean into the thermoclines of ocean systems (Sarmiento et al., 2004). The global distribution of $\mathrm{Si}^{*}$ indicates that SubAntarctic Mode Water (SAMW) acts as a significant source of nutrients to the thermocline in the Southern Hemisphere and the North Atlantic (Sarmiento et al., 2004; Palter et al., 2010). In contrast, North Pacific Intermediate Waters (NPIW) play a more important role in thermocline nutrient supply in the Pacific (Sarmiento et al., 2004; Palter et al., 2010). In addition to acting as a tracer, we propose that the distinct $\mathrm{Si}^{*}$ signatures of these water masses, negative in SAMW and positive in NPIW, may also play a role in dictating phytoplankton community responses to euphotic zone nutrient input. $\mathrm{Si}^{*}$ can be considered an important indicator of nutrient availability related to the requirement of diatoms (Ragueneau et al., 2000; Brzezinski et al., 2003). When sufficient light and nutrients (including iron) are available, diatoms accumulate biomass with silicate and nitrate at a molar ratio of $\sim 1: 1$ (Brzezinski et al., 2003, 2005). Consequently, for a diatom population to efficiently utilize all available nitrate, it might be expected that the ambient $\mathrm{Si}^{*}$ would have to be $>0 \mu \mathrm{M}$ (Ragueneau et al., 2000). Here, we investigated the possibility that the nature of the biological response instigated by upwelling mesoscale eddies, and the observed discrepancy in the contribution of large diatoms to phytoplankton communities between MWE and cyclonic eddies in the Atlantic and between cyclonic eddies in the North Atlantic and Pacific sub-tropical gyres, are related to the chemical composition of the upwelled waters impacting the euphotic zone.

\section{Methods}

\subsection{General field work}

The EDDIES project consisted of four cruises on the $\mathrm{R} / \mathrm{V}$ Oceanus over two summer field seasons (OC404-1 11 June-3 July 2004; OC404-4 25 July-12 August 2004; OC415-1 20 June-15 July 2005; and OC415-3 7-25 August 2005) in the Bermuda region of the Sargasso Sea (subtropical North Atlantic). E-Flux I (4-22 November 2004) and E-Flux III (10-28 March 2005) were conducted in the lee of the Hawaiian Islands aboard the R/V Kaimikai-O Kanaloa and R/V Wecoma, respectively. Prior to each cruise, candidate eddies in the appropriate location were detected and tracked using satellite data, including the geostationary operational environmental satellites (GOES-10 and AVHRR) to detect sea surface temperature (SST), MODIS imagery to monitor surface chlorophyll- $a$, and satellite altimetry data from the CCAR (http://cordc.ucsd.edu/projects/ satellite/altimetry/ccar/) (Dickey et al., 2008; Leben et al., 2002; Seki et al., 2001; Siegel et al., 1999). Each eddy was 
sampled by CTD hydrocasts at several sampling stations. These stations were strategically chosen to sample sections from the outside of each eddy and through the eddy centre of each feature. The locations of these stations were based on ongoing ADCP measurements and, in the EDDIES project, were supported by along-track XBT profiles $(0-700 \mathrm{~m})$ to quantify the main thermocline signal.

\subsection{Analytical measurements}

Discrete water samples and in situ vertical profiles of temperature and salinity were collected using CTD systems, which consisted of a rosette of Niskin bottles attached to a frame containing a Seabird 9/11+CTD. Discrete samples were taken using this system to measure parameters such as phytoplankton pigmentation and inorganic nutrient analysis. In addition to sampling standard depths throughout the euphotic zone, the phytoplankton community at the deep chlorophyll maximum (DCM) was specifically targeted with reference to the real-time output from the fluorometer on the CTD rosette. In the EDDIES project, nutrient measurements were collected using a highly sensitive nanomolar technique with long-path-length spectrophotometry ( $\mathrm{Li}$ and Hansell, 2008), and in the E-Flux project by a continuous segmented flow system consisting of components of both a Technicon Autoanalyser II ${ }^{\mathrm{TM}}$ and an Alpkem RFA $300^{\mathrm{TM}}$ (Rii et al., 2008). Phytoplankton pigment data were determined by HPLC analysis of the total phytoplankton community, as described previously (McGillicuddy et al., 2007; Rii et al., 2008). Discrete measurements from this sampling are now publicly available (through http://science. whoi.edu/users/olga/eddies/EDDIES_Project.html and http:// www.soest.hawaii.edu/oceanography/). In this analysis, total chlorophyll- $a$ concentration was used to estimate the relative phytoplankton abundance, while total fucoxanthin concentration was used to estimate the relative diatom abundance (Rii et al., 2008), with the ratio of fucoxanthin:chlorophyll$a$ providing an index of the proportional contribution of diatoms to total community biomass. One-way analysis of variance (one-way ANOVA) was used to compare differences in variables between different eddy types.

\subsection{Retrospective analysis of BATS data}

Eddy features affecting the BATS site in the period 19932002 have been previously identified (Mouriño-Carballido, 2009) using the analysis of eddy-field animations generated from the objective analysis of satellite altimetry for the domain spanning latitude $23-28^{\circ} \mathrm{N}$ and longitude $75-45^{\circ} \mathrm{W}$. Eddy features that exhibited a strong signal, that affected the BATS site for relatively long periods of time, and were influenced by the centre of the eddy features were used in this analysis; these features are described in MouriñoCarballido (2009). BATS sampling dates thus determined to be influenced by the centre of eddy features in the pe- riod 1993-2002 were therefore used to study the distributions of nitrate and silicate in the present analysis. Details of the BATS sampling scheme, analytical methods, data quality control and inter-calibration procedures appear in the BATS Methods Manual (Knap et al., 1993). Data are available from the BATS website at http://bats.bios.edu/.

\subsection{Whole Atlantic sections}

Meridional sections of $\mathrm{Si}^{*}$ throughout the Atlantic were constructed using the GLODAP data collection (Key et al., 2004; Sabine et al., 2005).

\section{Results}

Here we present results of nutrient profiles and phytoplankton pigment composition of mesoscale eddy features specifically targeted in research cruises to the Sargasso Sea region of the NASG (EDDIES project 2004-2005, McGillicuddy et al., 2007) and from mesoscale eddies that form in the lee of the Hawaiian islands (NPSG) (E-Flux project 2004, Benitez-Nelson et al., 2007). These in situ measurements have been complemented by analysis of mesoscale eddy features that affected the BATS location in the Sargasso Sea (Mouriño-Carballido, 2009). We used $\mathrm{Si}^{*}=\left[\mathrm{Si}(\mathrm{OH})_{4}\right]-$ $\left[\mathrm{NO}_{3}^{-}\right]$(Sarmiento et al., 2004) both as a tracer of water masses and as an indicator of the relative availability (or deficiency) of both nutrients for the phytoplankton community.

During the EDDIES and E-Flux programs a total of six cyclonic and two MWE were specifically targeted, and certain features were sampled on multiple occasions over time scales up to 2 months to assess the temporal development of the features. Three representative features of these programs were: (1) cyclonic eddy Opal (E-Flux program March 2005, Lat $19.522^{\circ} \mathrm{N}$ Long $-157.082^{\circ} \mathrm{W}$, NPSG); (2) cyclonic eddy C5 (EDDIES program June 2005, Lat $30.982^{\circ} \mathrm{N}$ Long $-66.180^{\circ} \mathrm{W}, \mathrm{NASG}$ ); and (3) MWE A4 (EDDIES program June-August 2005 , Lat $30.181^{\circ} \mathrm{N}$ Long $-68.159^{\circ} \mathrm{W}$, NASG). The locations of the eddies were determined remotely by satellite altimetry (Dickey et al., 2008; Siegel et al., 2008) and, more precisely, through in situ measurements collected at sea (Benitez-Nelson et al., 2007; McGillicuddy et al., 2007).

Figure 1 shows contour maps of vertical depth profiles of temperature (Fig. 1a-c), total chlorophyll- $a$ concentration on a log scale (Fig. 1d-f), total dissolved nitrate concentration (Fig. 1g-i) and $\mathrm{Si}^{*}$ (Fig. 1j-l) from approximately 150-km transects through the physical centres of the three representative mesoscale features. The physical perturbation associated with the "centre" of each eddy system can be seen from the temperature profiles; this is slightly off-centre in the transect of cyclonic eddy C5. The distribution of chlorophyll throughout each feature was dominated by a DCM (Fig. 1df). The DCM in the centres of cyclone Opal and MWE A4 is 


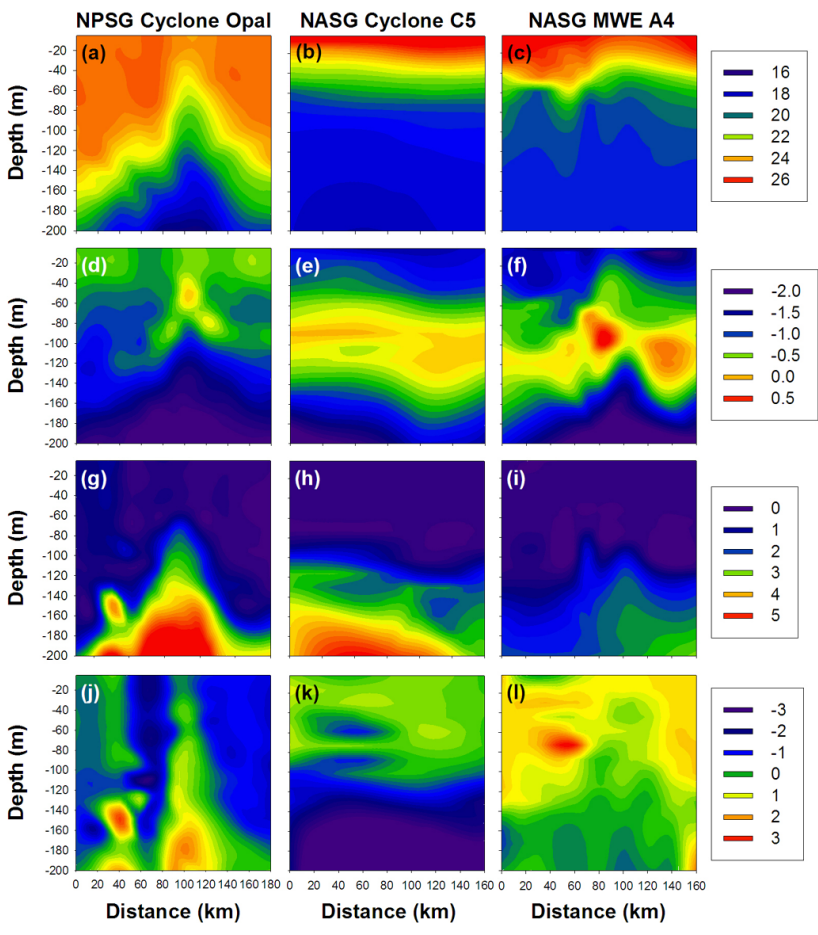

Fig. 1. Comparison of physical and chemical features in transects of vertical profiles $(0-200 \mathrm{~m})$ through the physical centre of three eddies. (a-c) show transects of temperature $\left({ }^{\circ} \mathrm{C}\right),(\mathbf{d}-\mathbf{f})$ transects of total chlorophyll- $a\left(\mathrm{mg} \mathrm{m}^{-3}\right.$; shown on a log scale), (g-h) transects of total dissolved nitrate $\left(\mu \mathrm{mol} 1^{-1}\right)$, and (i-l) $\mathrm{Si}^{*}\left(\mu \mathrm{mol} 1^{-1}\right)$. Cyclonic eddy Opal was sampled close to Hawai' $i$ in the NPSG (March 2005), while cyclonic eddy C5 and MWE A4 were sampled in the Sargasso Sea NASG, (June-August 2005).

a dominant feature, whereas in cyclonic eddy C5 chlorophyll is less enhanced with respect to the DCM community at the edge of the eddy. DCM form in well-stratified water columns throughout oligotrophic ocean systems and are normally located at the top of the nutracline (Fig. $1 \mathrm{~g}-\mathrm{i}$ ). The relative abundance of the macronutrient silicate $\left[\mathrm{Si}(\mathrm{OH})_{4}\right]$ over nitrate $\left[\mathrm{NO}_{3}^{-}\right]$, both measured in $\mu$ moll $1^{-1}$, can be seen from the contour plot of $\mathrm{Si}^{*}$ (Fig. $1 \mathrm{j}-1$ ). Both cyclonic eddy Opal and MWE A4 have water with positive $\mathrm{Si}^{*}$ in the eddy centre at depths that are close to the base of the DCM and so may influence the phytoplankton community. Cyclonic eddy C5, however, has water with negative $\mathrm{Si}^{*}$ at the eddy centre close to the DCM.

Temperature-salinity plots of two representative profiles of the central stations measured in MWE A4 and cyclonic eddy C5 demonstrate that the central stations of MWE A4 and cyclonic eddy C5 in the Sargasso Sea contained similar water masses (Fig. 2a). However, the depth distribution of these water masses is clearly very different (Fig. 2b). Specifically, for MWE A4, the mode water layer between $\sim 100$ and $500 \mathrm{~m}$ effectively isolates the DCM from the deeper thermocline waters that are found in close proximity to the base of the thermocline within C5 (Fig. 2b).
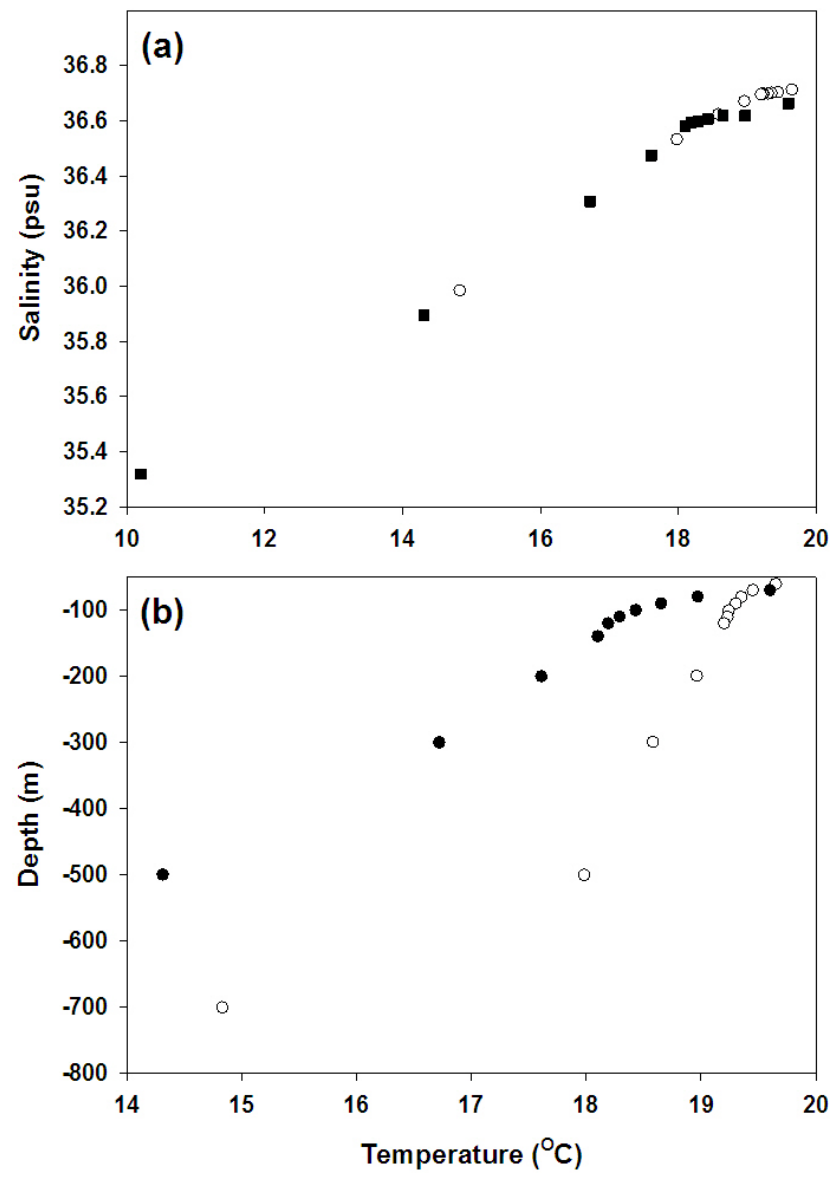

Fig. 2. Comparison of temperature and salinity profiles (a) and temperature-depth profiles (b) from the central station MWE A4 (white dots) and Cyclonic eddy C5 (black squares).

All three of the example eddy features have previously been shown to support chlorophyll biomasses in excess of what is normally measured at the Hawaiian Ocean Time Series (HOTS) and BATS at similar times of year (McGillicuddy et al., 2007). The highest chlorophyll concentration measured in the NASG MWE A4 was three orders of magnitude higher than anything previously measured at BATS (McGillicuddy et al., 2007). Microscopic analysis revealed that cyclonic eddy Opal supported diatom communities dominated by the large chain-forming diatoms Chaetoceros and Rhizosolenia spp. (Brown et al., 2008), whereas diatom communities supported by MWE A4 were dominated by Chaetoceros spp. only (Bibby et al., 2008). Previous studies have shown that cyclonic eddy C5 did not support diatom communities and was dominated by the cyanobacteria Synechococcus at levels higher than those seen in the background BATS community (Ewart et al., 2008).

In Fig. 3 we show the average phytoplankton community composition associated with the DCM at the eddy centre of a total of eight eddies studied as part of the EDDIES and E-Flux programmes. Due to nutrient exhaustion 

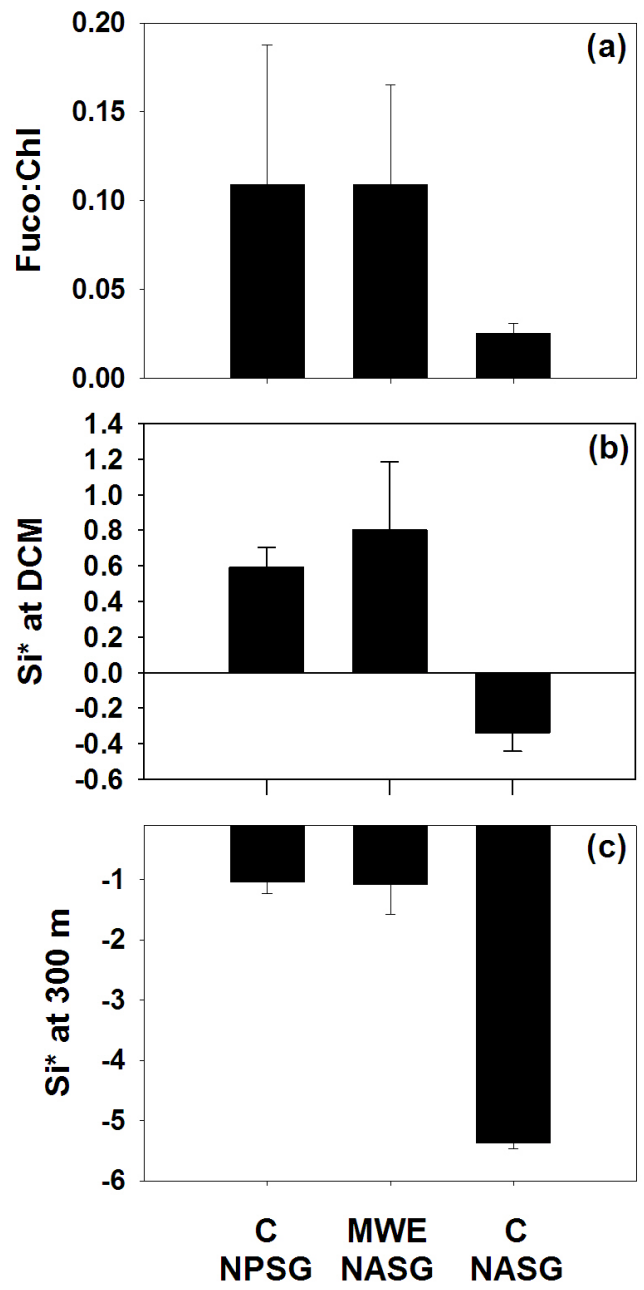

Fig. 3. The biological community sustained at the deep-chlorophyll maximum (DCM) at the central station of the three eddy types described in the paper, two from the Sargasso Sea (NASG) (MWE, $n=2$, and cyclonic eddy, $\mathrm{C}, n=4)$ and one from the Hawai'i region of the NPSG (cyclonic eddy, C, $n=2$ ). The DCM at the eddy centre station from each feature was sampled multiple times; averages are shown for each eddy type. The y-axis represents the ratio of fucoxanthin:chlorophyll- $a(\mathbf{a}), \mathrm{Si}^{*}$ at the DCM $\left(\mu \mathrm{mol} 1^{-1}\right)(\mathbf{b})$, and $\mathrm{Si}^{*}$ at $300 \mathrm{~m}\left(\mu \mathrm{mol} \mathrm{l}^{-1}\right)$ (c). Standard error bars are shown.

above and light limitation below (Cullen, 1982), the DCMassociated communities are those most affected by the perturbed nutrient profiles associated with mesoscale eddy features. Hence, any changes in community composition resulting from eddy activity are most likely to be observed here. For each eddy type (Cyclonic NPSG, Cyclonic NASG and MWE NASG), three parameters are shown: the ratio of fucoxanthin:chlorophyll- $a$, an index of the proportional contribution of diatoms to total community biomass (Fig. 3a); $\mathrm{Si}^{*}$ at the DCM, a measure of the relative availability of silicate over nitrate at the DCM (Fig. 3b); and $\mathrm{Si}^{*}$ at $300 \mathrm{~m}$, a measure of the relative availability of silicate over nitrate at a depth well below the euphotic zone but indicative of the potential ratio of nitrate and silicate supply to the euphotic zone (Fig. 3c). Each mesoscale feature was sampled on multiple occasions and the averages of each eddy type are reported (Cyclonic NPSG $n=2$, Cyclonic NASG $n=4$, and MWE NASG $n=2$ ). Absolute concentrations of the diatom marker pigment fucoxanthin and ratios of fucoxanthin:chlorophyll- $a$ indicated that the eddy types support different phytoplankton communities, with NPSG cyclones and NASG MWE, but not NASG cyclones, supporting significant populations of diatoms (Fig. 3a). Moreover, $\mathrm{Si}^{*}$ was lower in NASG cyclonic features at both the DCM and $300 \mathrm{~m}$, which is in clear contrast to the higher values found in the other two systems. One-way ANOVA revealed significant differences in $\mathrm{Si}^{*}$ at both the DCM and at $300 \mathrm{~m}$ (DCM, $p=0.0027, F=$ $7.76 ; 300 \mathrm{~m}, p<0.0000001, F=33.66)$ and the ratio of fucoxantin:chlorophyll ( $p<0.0131, F=5.11)$ between eddy types. Subsequent Tukey-Kramer means comparison tests confirmed that both $\mathrm{Si}^{*}$ (at both the DCM and $300 \mathrm{~m}$ ) and fucoxantin:chlorophyll were significantly $(\alpha=0.05)$ lower in cyclonic eddies within the NASG than both NASG modewater and NPSG cyclonic features, the latter two systems being indistinguishable at the $95 \%$ confidence level. Anticyclonic eddies, although not considered in this paper, generally support low biomass phytoplankton communities dominated by Prochlorococcus ecotypes (Ewart et al., 2008).

We also considered the mesoscale eddies that have affected the BATS site in the Sargasso Sea (NASG). These features have been identified through previous studies (Mouriño-Carballido, 2009; Sweeney et al., 2003) and indicate that while MWE support diatom populations, cyclonic eddies in the Sargasso Sea typically support enhanced Synechococcus populations. In Fig. 4, we present the averaged vertical profiles from $0-400 \mathrm{~m}$ (Fig. $4 \mathrm{a}-\mathrm{c}$ ) and from 0 $1000 \mathrm{~m}$ (Fig. 4d-f) of the relative abundance of silicate over nitrate, $\mathrm{Si}^{*}$, as well as both silicate concentration $\left[\mathrm{Si}(\mathrm{OH})_{4}\right]$ and nitrate concentration $\left[\mathrm{NO}^{3-}\right]$. These results show that the base of the euphotic zone at the BATS site is affected by different water masses with a different chemical composition during cyclonic and MWE events (Fig. 4d-f). Despite these data averaging numerous features that affected BATS throughout the year, and that the influence of eddies at the BATS site is inferred both remotely from analysis of sea level and from in situ hydrographic sampling, the trend observed in mesoscale eddies studied in situ in spring/summer seasons during the EDDIES program is maintained. $\mathrm{Si}^{*}$ is always positive at depths from 0 to the inferred nutracline (where nitrate becomes detectable using standard colorimetric techniques) (Fig. 4a and c), presumably due to surface non-siliceous phytoplankton growth stripping all the available nitrate from the system and leaving residual silicate (Fig. 4b). At depths below $100 \mathrm{~m}, \mathrm{Si}^{*}$ becomes negative $\left(\mathrm{Si}^{*}=0 \mu \mathrm{moll}^{-1}\right.$ is shown in Fig. $4 \mathrm{a}$ and $\mathrm{d}$ as a vertical dotted line), and from this point to $\sim 500 \mathrm{~m} \mathrm{Si}^{*}$ is more negative in cyclonic features than MWE features, This indicates that 

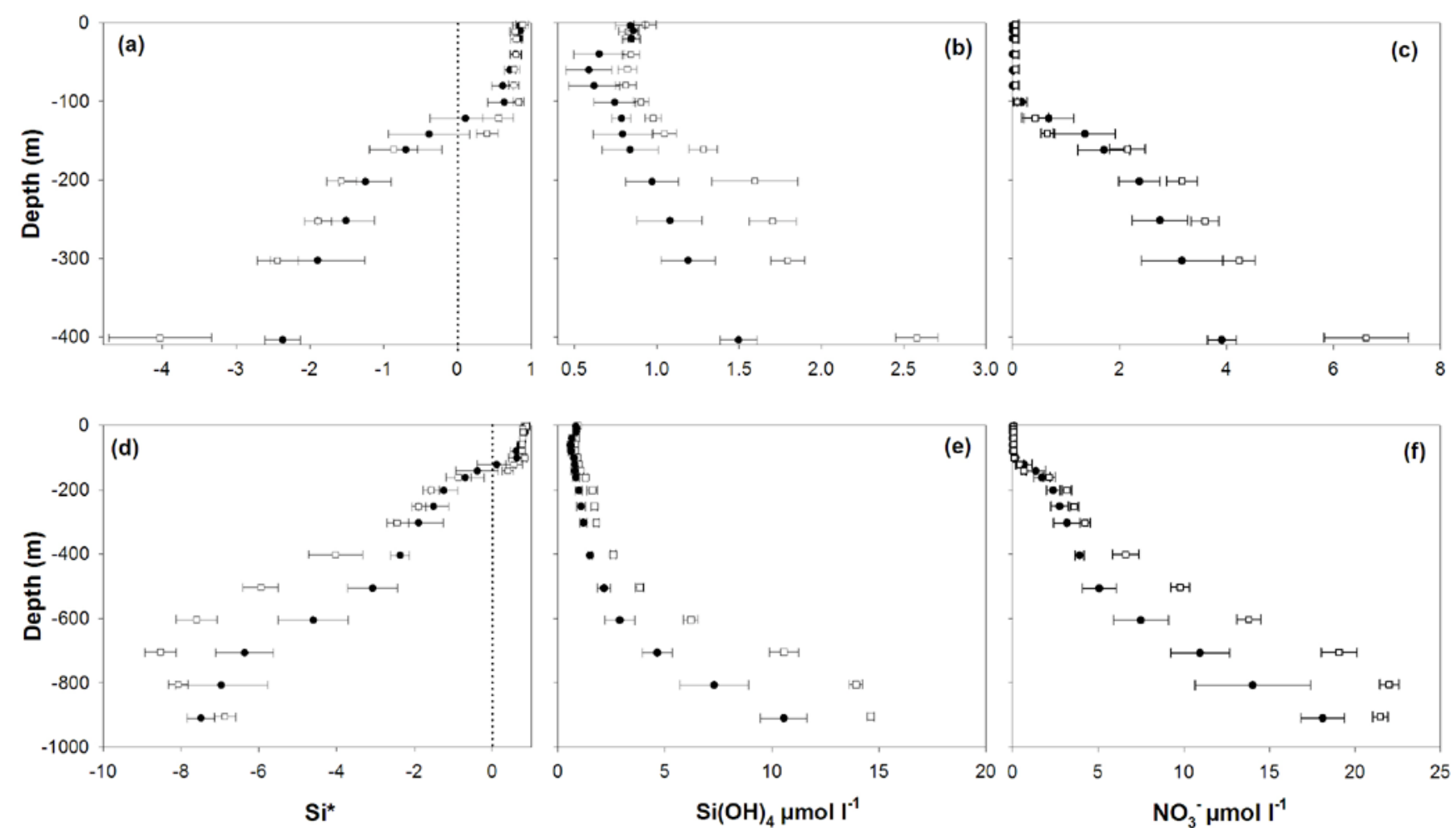

Fig. 4. Depth profiles of $\mathrm{Si}^{*}\left(\mu \mathrm{mol} 1^{-1}\right)$, the concentration of silicate $\left(\mathrm{Si}(\mathrm{OH})_{4} \mu \mathrm{moll}^{-1}\right)$ and the concentration of nitrate $\left(\mathrm{NO}_{3}^{-} \mu \mathrm{mol} \mathrm{l}^{-1}\right)$ in eddy features that have affected the Bermuda Atlantic Time-Series Study (BATS) over the past decade. $\mathrm{Si}^{*}=0\left(\mu \mathrm{mol} 1^{-1}\right)$ is shown by a dotted line. Averages of six cyclonic (white squares) and four mode-water eddy (black circles) features are shown (standard error bars are shown on the graph). (a-c) show the depth profiles to $400 \mathrm{~m}$, while (d-f) show profiles to $1000 \mathrm{~m}$.

the trend observed in the EDDIES program (Fig. 1) is consistent with mesoscale features sampled over the past decade at the BATS site.

\section{Discussion}

In this paper we identify the tracer $\mathrm{Si}^{*}$ (the relative abundance of silicate over nitrate) as a key parameter in determining the character of the phytoplankton community sustained by upwelling mesoscale eddies in the NASG and NPSG. In the Sargasso Sea, mesoscale eddies have been proposed to be an important mechanism by which new nutrients enter the euphotic zone and stimulate primary production (Jenkins et al., 1988; McGillicuddy et al., 1999; Oschlies, 2002). While this is clearly the case, there has emerged a clear and consistent trend relating to the nature of the biological response, namely that MWE support a phytoplankton community a significant fraction of which is diatoms and cyclonic eddies support prokaryote-dominated populations (Bibby et al., 2008; Mouriño-Carballido, 2009; Sweeney et al., 2003). This has clear implications for the capacity for export within each type of feature and should be considered when deriving mesoscale-resolving models (McGillicuddy et al., 1999; Oschlies, 2002; Oschlies and Garcon, 1998), However, both features can maintain enhanced phytoplankton populations for significant periods ( $>6$ weeks) and the mechanism for the marked community difference has remained enigmatic (Bibby et al., 2008; McGillicuddy et al., 1999). A mechanism of enhanced nutrient supply in MWE involving the interaction of wind stress on anti-cyclonic features has been suggested to be responsible for the overall biological response (McGillicuddy et al., 2007). However, this may not explain why there is a difference in the phytoplankton community structure or why cyclonic eddies in the NPSG are capable of maintaining communities of large diatoms (BenitezNelson et al., 2007).

The results presented here suggest that mesoscale eddy features in the Sargasso Sea are chemically preconditioned to support different types of phytoplankton community with implications for the potential for export from different features. Nitrate supplied to the euphotic zone is completely utilized within the DCM, resulting in extremely low concentrations above this feature (Figs. 1 and 4). As a result, the rate of nutrient supply will likely be a key determinant of the overall magnitude of the biological response (McGillicuddy et al., 2007). However, the ratio of supplied nutrients will be important in determining the structure of the phytoplankton community. Importantly, this influence on community structure (but not necessarily overall biomass) can occur even 
if the silicate concentration and/or supply within the waters influencing the base of the euphotic zone are identical. Indeed, the difference in $\mathrm{Si}^{*}$ between MWE and cyclones in the NASG is principally determined by differences in nitrate below the euphotic zone rather than silicate. For example, the silicate concentration in both MWE and cyclones at $300 \mathrm{~m}$ is about $2 \mu \mathrm{mol}^{-1}\left( \pm 0.5 \mu \mathrm{mol}^{-1}\right)$ during the EDDIES project.

The residual silicate concentration above the DCM is similar in both cyclonic and MWE features $\left(\sim 1 \mu \mathrm{moll}^{-1}\right.$, Fig. 4$)$, potentially indicative of the concentration at which diatoms are out-competed for any remaining nitrate (Egge and Aksnes, 1992). Assuming that diatoms utilize silicate down to $\sim 1 \mu \mathrm{mol} \mathrm{l}^{-1}$ alongside an equimolar consumption of nitrate (Brzezinski et al., 2003) and that non-siliceous phytoplankton utilize any remaining nitrate, a simple model of the expected community structure response can be formulated (Fig. 5a). At any given silicate concentration for supply waters, the resultant community structure (i.e. the contribution of diatoms to the total standing stock) is determined by $\mathrm{Si}^{*}$ (or effectively the excess of nitrate available after complete silicate removal). Although highly simplistic, for example neglecting any differential loss terms for different components of the community, this simple calculation at least qualitatively captures the observed relationship between MWE and cyclonic eddies (Fig. 5b). In MWE, where silicate and nitrate are both supplied and utilized at the DCM at relatively high $\mathrm{Si}^{*}$, diatoms become a significant fraction of the community. However, in cyclonic eddies where silicate and nitrate are supplied at lower $\mathrm{Si}^{*}$, and hence can only both be fully utilized at the DCM at a lower overall silicate/nitrate ratio, diatoms comprise a smaller fraction of the community.

Again we emphasize that, although complete nutrient depletion within the DCM drives the community structure to be dependent on the ratio of silicate to nitrate supply, the physical rate of supply will then determine the overall magnitude of biomass sustained in each eddy. Although this rate can vary during the lifetime of a particular feature, it appears to be lower in cyclonic eddies than MWE (McGillicuddy et al., 2007; Ledwell et al., 2008). Consequently, the overall high phytoplankton biomass within MWE may be driven by physical factors, while we suggest that the greater proportion of diatoms is a consequence of the higher $\mathrm{Si}^{*}$ at the base of the euphotic zone. In contrast cyclonic eddies in the Sargasso Sea are characterized by lower phytoplankton biomass dominated by smaller prokaryotes. Moreover, cyclonic eddies in the NPSG have a higher $\mathrm{Si}^{*}$ than cyclonic eddies in the Sargasso Sea and hence appear to be able to support diatom populations even with a potentially low rate of nutrient supply (Benitez-Nelson et al., 2007). Therefore, we suggest that it is only within NASG MWE (and NPSG cyclonic eddies) that nutrient inputs at relative high $\mathrm{Si}^{*}$ can result in higher diatom standing stocks within the DCM.
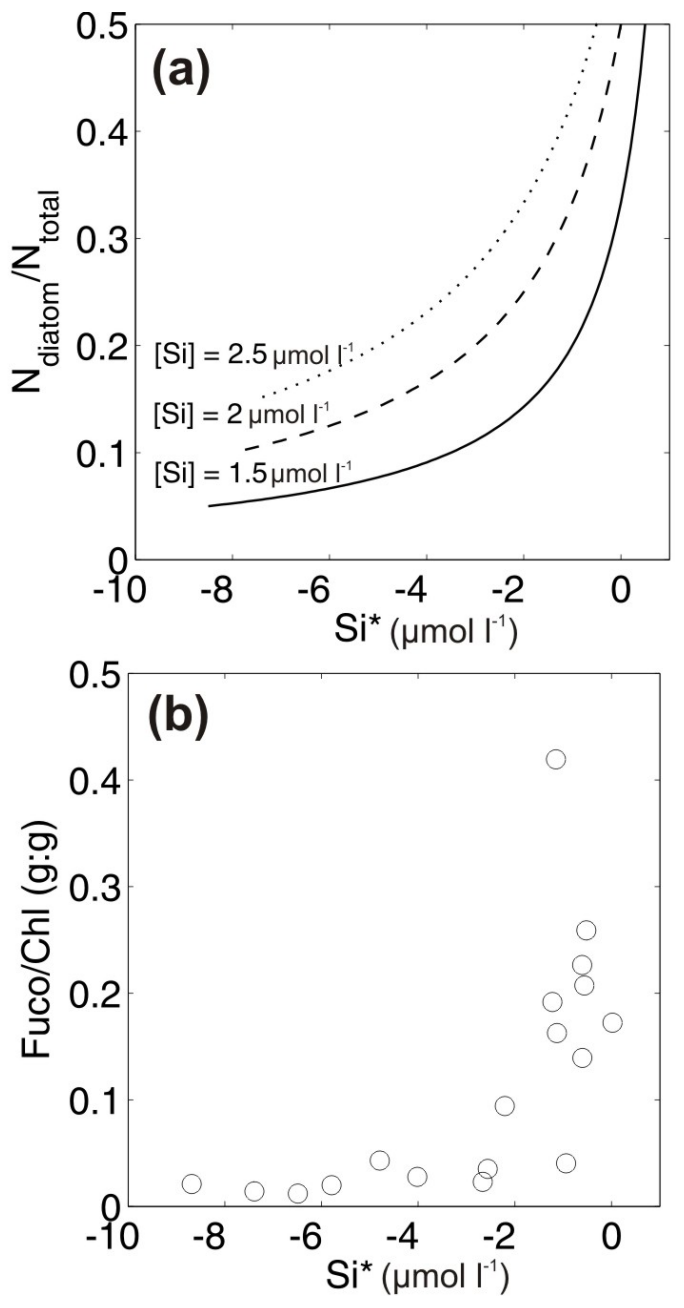

Fig. 5. Theoretical calculation of the fractional contribution of diatoms to overall community biomass (as indicated by diatom over total phytoplankton nitrogen, $\mathrm{N}_{\text {diatom }} / \mathrm{N}_{\text {total }}$ ) as a function of $\mathrm{Si}^{*}\left(\mu \mathrm{mol} \mathrm{l}^{-1}\right)$ within a hypothetical supply water at 3 set silicate concentrations representative of waters from around $300 \mathrm{~m}$ in the NASG (a). The relationship between observed $\mathrm{Si}^{*}\left(\mu \mathrm{mol} 1^{-1}\right)$ at $300 \mathrm{~m}$ and the fucoxanthin:chlorophyll ratio (white dots) (b), an index of the fractional contribution of diatoms to community biomass observed at the DCM within cyclonic and MWE sampled in the NASG as part of the EDDIES project.

The observation that cyclonic eddies in the NPSG support diatom populations (Benitez-Nelson et al., 2007; Bibby et al., 2008) clearly indicates that the mechanism responsible for governing the dominance or not of diatoms in oligotrophic eddy communities is not a cyclone-specific physical mechanism. The nature of the biological community response to eddy activity in oligotrophic systems therefore appears to be predetermined by the characteristic waters influencing the DCM within each eddy feature. In Fig. 6, we provide a simplified schematic of the potential sources for these waters in cyclonic and MWE features in the Atlantic, 


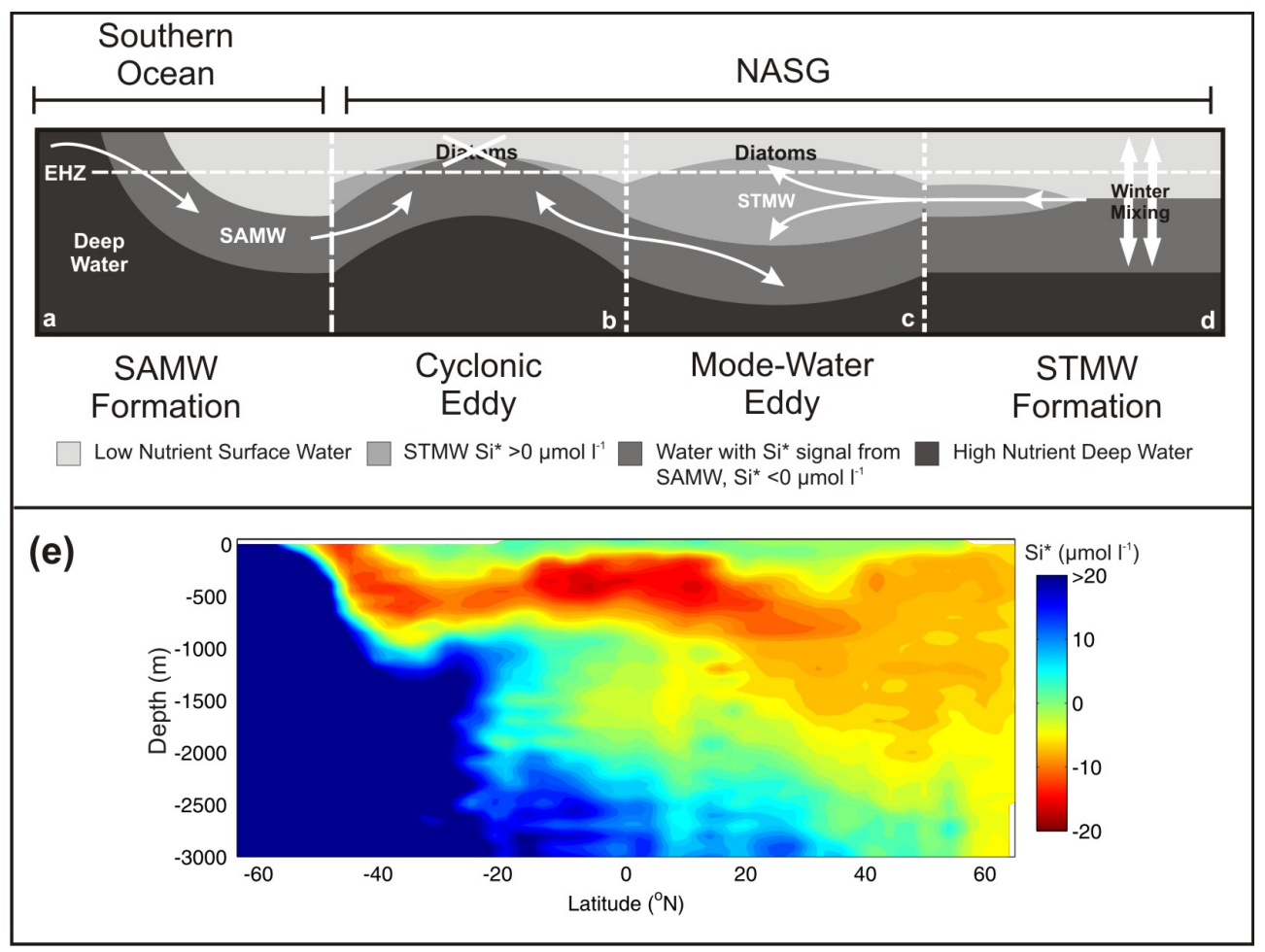

Fig. 6. Proposed model of the source of nutrients that affect the thermocline in the North Atlantic Sub-tropical Gyre (NASG). The figure shows a stylized section of $\mathrm{Si}^{*}$ in both the Southern Ocean and the NASG. Sub-Antarctic Mode-Water (SAMW), where a negative Si* is formed in Antarctica from upwelling of nutrient-rich deep waters followed by subsequent northward Ekman transport and concurrent preferential silicate removal (a). Water with a $\mathrm{Si}^{*}$ signal derived from SAMW is transported north and can reach the thermocline in the NASG through the action of mesoscale cyclonic eddies (b), but is downwelled by the action of mesoscale mode-water eddies (c) and uncoupled from the thermocline. Winter mixing of SAMW and surface water (d) on the northern boundary of the NASG leads to the formation of sub-tropical mode water (STMW) with positive $\mathrm{Si}^{*}$ that impacts the base of the euphotic zone (EHZ, dashed horizontal line) in the NASG through the action of mesoscale mode-water eddies (c). This mechanism determines whether the phytoplankton community stimulated by mesoscale eddies can sustain significant diatom populations. (e) Latitudinal section of $\mathrm{Si}^{*}$ through the Atlantic from GLODAP data.

alongside a section of $\mathrm{Si}^{*}$ within the upper $3000 \mathrm{~m}$, which is clearly suggestive of the southern source of the low $\mathrm{Si}^{*}$ signal within the thermocline (Sarmiento et al., 2004). The sub-DCM waters within cyclonic eddies are more influenced by SAMW with low $\mathrm{Si}^{*}$, as used as a tracer of this water mass (Sarmiento et al., 2004). The low Si* in SAMW is the result of the selective silicate pump in the Sub-Antarctic, whereby iron-limited phytoplankton populations, dominated by diatoms, are heavily silicified (have a $\mathrm{Si}$ : N ratio $>1$ ), resulting in relatively more silicate than nitrate being exported, leaving a low $\mathrm{Si}^{*}$ signature (Sarmiento et al., 2004; Boyd et al., 2001; Hutchins and Bruland, 1998; Takeda, 1998). We suggest that this mechanism caused by iron-limitation in the Southern Ocean predetermines the biological effects of cyclonic eddies in the Sargasso Sea some 6000 miles and 50$100 \mathrm{yr}$ away (Zuo et al., 2009). However, the base of the DCM in MWE is more influenced by Sub-Tropical ModeWater (STMW) that is formed during winter mixing in the northern boundary of the NASG (Palter et al., 2005, 2010; McCartney, 1982; Talley and Raymer, 1982). Surface waters in the NASG have a high $\mathrm{Si}^{*}$ owing to the preferential removal of nitrate over silicate by non-silicifying phytoplankton over the summer. During winter in the STMW formation region, these surface waters will mix with deeper thermocline waters containing the lower $\mathrm{Si}^{*}$ signature of SAMW. STMW thus forms with a higher $\mathrm{Si}^{*}$ than these lower thermocline waters. Consequently, when a MWE lens impacts the euphotic zone it is has the capacity to maintain a significantly enhanced contribution of diatoms to overall community biomass. The combination of our proposed mechanism with an overall enhanced nutrient flux also likely explains the observed increase in biogeogenic silicate production at BATS when mode waters influence the site (Krause et al., 2010) and suggest that the extent of winter mixing to the north could have a direct effect on the $\mathrm{Si}^{*}$ of STMW and therefore the biological response to MWE in this region. We believe this is the first demonstration of how mechanisms such as the selective silicate pump in the Southern Ocean, which are temporally and spatially separate from the Sargasso Sea, can affect biology and export in this region. The 
study further illustrates how large-scale circulation patterns can govern differences in biogeochemical responses between the North Atlantic and Pacific sub-tropical gyres.

Acknowledgements. The authors thank Dennis McGillicuddy, Claudia Benitez-Nelson, Paul Falkowski and the other principal investigators, post-docs and students, who led and were involved in sampling in the NSF-funded EDDIES and E-Flux projects. Special thanks go to the captain and crews of the R/V Oceanus, R/V Welcoma and R/V Kaimikai $O$ Kanaloa. Thanks also to those involved in the collection, preparation and analysis of data from the BATS program. Special thanks go to Adrian Martin and Rod Johnson for useful discussions in the preparation of this manuscript, and the comments of two anonymous reviewers and Larry Anderson which considerably improved an earlier version. The authors are funded by the UK NERC (grant number NE/F010257/1).

Edited by: U. Riebesell

\section{References}

Benitez-Nelson, C. R., Bidigare, R. R., Dickey, T. D., Landry, M. R., Leonard, C. L., Brown, S. L., Nencioli, F., Rii, Y. M., Maiti, K., Becker, J. W., Bibby, T. S., Black, W., Cai, W.-J., Carlson, C. A., Chen, F., Kuwahara, V. S., Mahaffey, C., McAndrew, P. M., Quay, P. D., Rappe, M. S., Selph, K. E., Simmons, M. P., and Yang, E. J.: Mesoscale eddies drive increased silica export in the subtropical pacific ocean, Science, 316, 1017-1021, doi:10.1126/science.1136221, 2007.

Bibby, T. S., Gorbunov, M. Y., Wyman, K. W., and Falkowski, P. G.: Photosynthetic community responses to upwelling in mesoscale eddies in the subtropical north atlantic and pacific oceans, DeepSea Res. Pt. II, 55, 1310-1320, 2008.

Bibby, T. S., Zhang, Y. A., and Chen, M.: Biogeography of photosynthetic light-harvesting genes in marine phytoplankton, PLoS ONE, 4(2), e4601, doi:10.1371/journal.pone.0004601, 2009.

Boyd, P. W., Crossley, A. C., DiTullio, G. R., Griffiths, F. B., Hutchins, D. A., Queguiner, B., Sedwick, P. N., and Trull, T. W.: Control of phytoplankton growth by iron supply and irradiance in the subantarctic southern ocean: Experimental results from the saz project, J. Geophys. Res., 106, C12, doi:10.1029/2000JC000348, 2001.

Brown, S. L., Landry, M. R., Selph, K. E., Jin Yang, E., Rii, Y. M., and Bidigare, R. R.: Diatoms in the desert: Plankton community response to a mesoscale eddy in the subtropical north pacific, Deep-Sea Res. Pt. II, 55, 1321-1333, 2008.

Brzezinski, M. A., Dickson, M. L., Nelson, D. M., and Sambrotto, R.: Ratios of si, c and n uptake by microplankton in the southern ocean, Deep-Sea Res. Pt. II, 50, 619-633, 2003.

Brzezinski, M. A., Jones, J. L., and Demarest, M. S.: Control of silica production by iron and silicic acid during the southern ocean iron experiment (sofex), Limnol. Oceanogr., 50, 810-824, 2005.

Cullen, J. J.: The deep chlorophyll maximum: Comparing vertical profiles of chlorophyll a, Can. J. Fish. Aquat. Sci., 39, 791-803, 1982.

Dickey, T. D., Nencioli, F., Kuwahara, V. S., Leonard, C., Black, W., Rii, Y. M., Bidigare, R. R., and Zhang, Q.: Physical and bio-optical observations of oceanic cyclones west of the island of hawai'i, Deep-Sea Res. Pt. II, 55, 1195-1217, 2008.
Ducklow, H. S., Steinberg, D. K., and Buesseler, K. O.: Upper ocean carbon export and the biological pump, Oceanography, 14, 50-58, 2001.

Egge, J. K. and Aksnes, D. L.: Silicate as regulating nutrient in phytoplankton competition, Mar. Ecol.-Prog. Ser., 83, 281-289, 1992.

Ewart, C. S., Meyers, M. K., Wallner, E. R., McGillicuddy Jr., D. J., and Carlson, C. A.: Microbial dynamics in cyclonic and anticyclonic mode-water eddies in the northwestern sargasso sea, Deep-Sea Res. Pt. II, 55, 1334-1347, 2008.

Falkowski, P. G., Ziemann, D., Kolber, Z., and Bienfang, P. K.: Role of eddy pumping in enhancing primary production in the ocean, Nature, 352, 55-58, 1991.

Hutchins, D. A. and Bruland, K. W.: Iron-limited diatom growth and si:N uptake ratios in a coastal upwelling regime, Nature, 393, 561-564, 1998.

Jenkins, W. J., Webb, D. J., Merlivat, L., and Roether, W.: The use of anthropogenic tritium and helium-3 to study subtropical gyre ventilation and circulation [and discussion], Philos. T. R. Soc. S.-A, 325, 43-61, doi:10.1098/rsta.1988.0041, 1988.

Key, R. M., Kozyr, A., Sabine, C. L., Lee, K., Wanninkhof, R., Bullister, J., Feely, R. A., Millero, F., Mordy, C. W., and Peng, T.-H.: A global ocean carbon climatology: Results from Global Data Analysis Project (GLODAP), Global Biogeochem. Cy., 18, GB4031, doi:10.1029/2004GB002247, 2004,

Knap, A. H., Michaels, A. F., Dow, R. L., Johnson, R. J., Gundersen, K., Sorensen, J. C., Close, A., Howse, F., Hammer, M., Bates, N. R., Doyle, A., and Waterhouse, T.: BATS methods manual, version 3, US JGOFS Planning Office, Woods Hole, MA, USA, 1993.

Krause, J. W., Nelson, D. M., and Lomas, M. W.: Production, dissolution, accumulation, and potential export of biogenic silica in a sargasso sea mode-water eddy, Limnol. Oceanogr., 55, 569-579, 2010.

Leben, R. R., Born, G. H., and Engebreth, B. R.: Operational altimeter data processing for mesoscale monitoring, Mar. Geod., 25, 3-18, 2002.

Ledwell, J. R., McGillicuddy, D. J., and Anderson, L. A.: Nutrient flux into an intense deep chlorophyll layer in a mode-water eddy, Deep-Sea Res. Pt. II, 55, 1139-1160,2008.

Li, Q. P. and Hansell, D. A.: Nutrient distributions in baroclinic eddies of the oligotrophic north atlantic and inferred impacts on biology, Deep-Sea Res. Pt. II, 55, 1291-1299, 2008.

Martin, A. P. and Pondaven, P.: On estimates for the vertical nitrate flux due to eddy pumping, J. Geophys. Res., 108, 3359, doi:10.1029/2003jc001841, 2003.

McCartney, M. S.: The subtropical recirculation of mode waters, J. Mar. Res., 40, 427-464, 1982.

McGillicuddy Jr., D. J., Johnson, R., Siegel, D. A., Michaels, A. F., Bates, N. R., and Knap, A. H.: Mesoscale variations of biogeochemical properties in the sargasso sea, J. Geophys. Res., 104, 13381-13394, doi:10.1029/1999jc900021, 1999.

McGillicuddy Jr., D. J., Anderson, L. A., Bates, N. R., Bibby, T., Buesseler, K. O., Carlson, C. A., Davis, C. S., Ewart, C., Falkowski, P. G., Goldthwait, S. A., Hansell, D. A., Jenkins, W. J., Johnson, R., Kosnyrev, V. K., Ledwell, J. R., Li, Q. P., Siegel, D. A., and Steinberg, D. K.: Eddy/wind interactions stimulate extraordinary mid-ocean plankton blooms, Science, 316, 10211026, doi:10.1126/science.1136256, 2007. 
Mouriño-Carballido, B.: Eddy-driven pulses of respiration in the sargasso sea, Deep-Sea Res. Pt. I, 56, 1242-1250, 2009.

Oschlies, A.: Can eddies make ocean deserts bloom?, Global Biogeochem. Cy., 16, 1106, doi:10.1029/2001gb001830, 2002.

Oschlies, A. and Garcon, V.: Eddy-induced enhancement of primary production in a model of the north atlantic ocean, Nature, 394, 266-269, 1998.

Palter, J. B., Lozier, M. S., and Barber, R. T.: The effect of advection on the nutrient reservoir in the north atlantic subtropical gyre, Nature, 437, 687-692, 2005.

Palter, J. B., Sarmiento, J. L., Gnanadesikan, A., Simeon, J., and Slater, R. D.: Fueling export production: nutrient return pathways from the deep ocean and their dependence on the Meridional Overturning Circulation, Biogeosciences, 7, 3549-3568, doi:10.5194/bg-7-3549-2010, 2010.

Ragueneau, O., Tréguer, P., Leynaert, A., Anderson, R. F., Brzezinski, M. A., DeMaster, D. J., Dugdale, R. C., Dymond, J., Fischer, G., François, R., Heinze, C., Maier-Reimer, E., Martin-Jézéquel, V., Nelson, D. M., and Quéguiner, B.: A review of the si cycle in the modern ocean: Recent progress and missing gaps in the application of biogenic opal as a paleoproductivity proxy, Global Planet. Change, 26, 317-365, 2000.

Rii, Y. M., Brown, S. L., Nencioli, F., Kuwahara, V., Dickey, T., Karl, D. M., and Bidigare, R. R.: The transient oasis: Nutrientphytoplankton dynamics and particle export in hawaiian lee cyclones, Deep-Sea Res. Pt. II, 55, 1275-1290, 2008.

Sabine, C. L., Key, R. M., Kozyra, A., Feely, R. A., Wanninkhof, R., Millero, F. J., Peng, T.-H., Bullister, J. L., and Lee, K.: Global Ocean Data Analysis Project: Results and data, ORNL/CDIAC145, NDP-083, Carbon Dioxide Inf. Anal. Cent., Oak Ridge Natl. Lab., US Dept. of Energy, Oak Ridge, Tenn., 110 pp., 2005.

Sarmiento, J. L., Gruber, N., Brzezinski, M. A., and Dunne, J. P.: High-latitude controls of thermocline nutrients and low latitude biological productivity, Nature, 427, 56-60, 2004.
Seki, M. P., Polovina, J. J., Brainard, R. E., Bidigare, R. R., Leonard, C. L., and Foley, D. G.: Biological enhancement at cyclonic eddies tracked with goes thermal imagery in hawaiian waters, Geophys. Res. Lett., 28, 1583-1586, doi:10.1029/2000g1012439, 2001.

Siegel, D. A., Mcgilliguddy, D. J., and Fields, E. A.: Mesoscale eddies, satellite altimetry, and new production in the sargasso sea, American Geophysical Union, Washington, DC, ETATS-UNIS, 1999.

Siegel, D. A., Court, D. B., Menzies, D. W., Peterson, P., Maritorena, S., and Nelson, N. B.: Satellite and in situ observations of the bio-optical signatures of two mesoscale eddies in the sargasso sea, Deep-Sea Res. Pt. II, 55, 1218-1230, 2008.

Sweeney, E. N., McGillicuddy, D. J., and Buesseler, K. O.: Biogeochemical impacts due to mesoscale eddy activity in the sargasso sea as measured at the bermuda atlantic time-series study (BATS), Deep-Sea Res. Pt. II, 50, 3017-3039, 2003.

Takeda, S.: Influence of iron availability on nutrient consumption ratio of diatoms in oceanic waters, Nature, 393, 774-777, 1998.

Talley, L. D. and Raymer, M. E.: Eighteen degree water variability, J. Mar. Res. (suppl.), 40, 757-775, 1982.

Vaillancourt, R. D., Marra, J., Seki, M. P., Parsons, M. L., and Bidigare, R. R.: Impact of a cyclonic eddy on phytoplankton community structure and photosynthetic competency in the subtropical north pacific ocean, Deep-Sea Res. Pt. I, 50, 829-847, 2003.

Volk, Y. and Hoffert, M. I.: Ocean carbon pumps: Analysis of relative strengths and efficiencies in ocean-drived atmospheric $\mathrm{CO}_{2}$ changes, Geophy. Monog. Series, 32, 99-100, 1985.

Zuo, H., Naveira Garabato, A. C., New, A. L., and Oschlies, A.: Mechanisms of Subantarctic Mode Water upwelling in a hybrid coordinate general circulation model, Ph.D. thesis, University of Southampton, UK, 2009. 